\title{
When technology is taken for granted: the paradox of co-working
}

Maria Laura Toraldo, University of Milan Maddalena Sorrentino, University of Milan

Lia Tirabeni, University of Milan-Bicocca

NOT FOR CIRCULATION, PLEASE CITE AS: Toraldo M.L., Sorrentino, M., Tirabeni, L. (2020) When technology is taken for granted: the paradox of co-working, 17th Conference of the Italian Chapter of AIS, ITAIS 2020, 16-17.10, University of ChietiPescara (Italy) 


\section{Co-working: a response to conventional understandings of work}

- Productivity is decoupled from physical location and set hours (Gregg and Kneese, 2020).

- Commitment to work is a personal endeavor not associated to being physically at one's desk (Taylor \& S. Luckman, 2018)

- Self-regulation has supplanted traditional forms of control, regulation and rewards (Fleming, 2009)

- ICT applications and platforms as the bricks that make possible the functioning of co-working spaces (Richardson, 2017) 


\section{ICT and the role of technology in co-working studies}

- Co-working offices are workspaces enabled by digital technologies and sometimes producing 'born digital' businesses"

- "This work is thus 'digital' in that it occurs through software, hardware and connectivity affording the possibilities of smaller, self-organised producer units" (Richardson, 2017).

- ICTs are deemed critical variables (or enabling resources) for the diffusion of more flexible forms of work, outside of traditional workspaces 


\section{A vague use of the notion of ICT}

Lack of explanations on how technology:

- Enables the functioning of co-working spaces

- Informs organizational design and practices within co-working spaces

-What are the main debates around co-working?

- How is technology placed within those debates? 


\section{Research strategy and method}

- A scoping review (Arksey \& O'Malley, 2005) $\rightarrow$ to "map" the broad phenomenon of coworking and its key characteristics.

- An exploratory review of academic articles on the topic (2005-2020).

- About 60 papers reviewed from different disciplines

e.g. economic geography, urban studies, communication studies, sociology, organization studies and management. 


\section{The collaborative dimension}
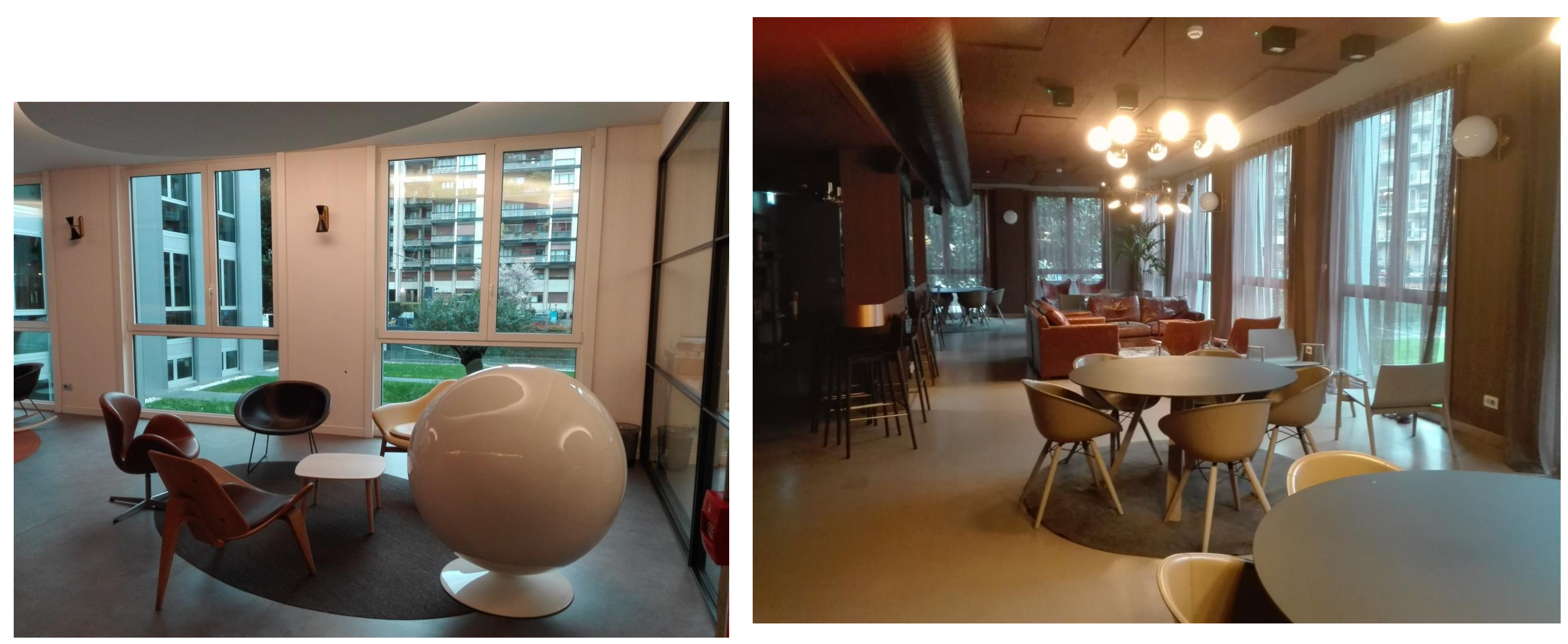

Source: photos taken by authors 


\section{The aesthetic dimension}
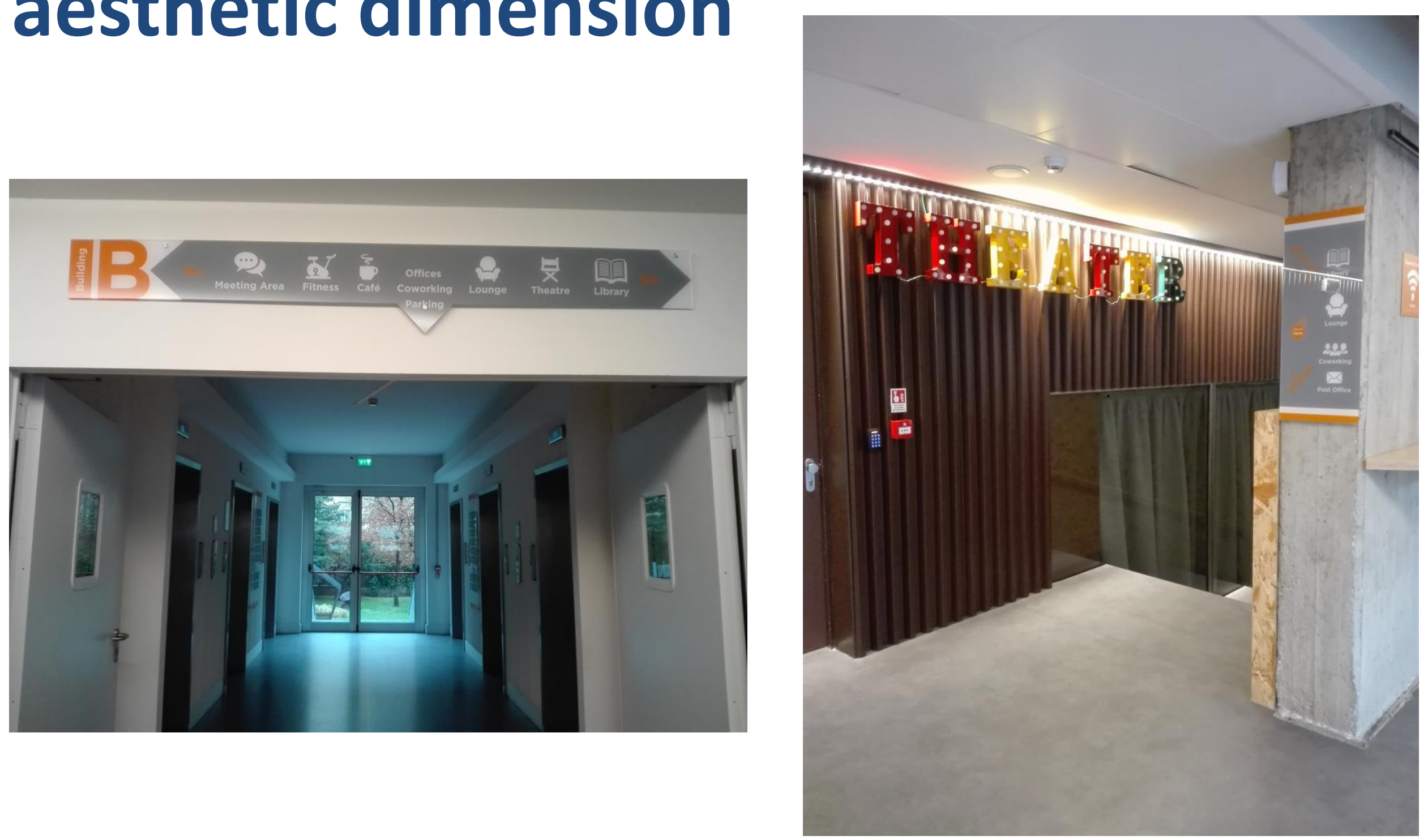
What is the place of technology within the debate on co-working?

- ICT is described mainly in a cursory 'nominal' way.

- ICT is infrastructural, it so taken for granted to have become invisible.

- ICT is celebrated as enabling radical transformations, interlinked with future-oriented grand aspirations 


\section{Common views of Technology $1 / 2$}

\section{Nominal view}

- Generic terms - including: digital technology, technological change, 'digital platforms - are used as mere background information.

\section{Tool view}

- ICTs are seen as tools. (ex.co-workers manage to reconcile their jobs and social relationships through technology) 


\section{Common views of Technology $2 / 2$}

\section{Proxy view}

- Key aspects of technology may be cap-tured through surrogate measures

5. Computational view

- The focus is on technical features of artefacts

6. Ensemble view

- ICT is analysed in association with organi-zational context of use 


\section{What is the place of technology within the debate on co-working?}

\begin{tabular}{|l|l|l|}
\hline View of technology & \multicolumn{1}{|c|}{ Conceptualization of technology } & Examples from the content analysis \\
\hline Nominal view & $\begin{array}{l}\text { References to technology are either inci- } \\
\text { dental or used as background information }\end{array}$ & $\begin{array}{l}\text { Richardson, L., Sharing as a postwork style: digital work and the co- } \\
\text { working office. Cambridge Journal of regions, economy and society, } \\
\text { 2017. 10(2): p. 297-310 }\end{array}$ \\
\hline Tool view & $\begin{array}{l}\text { Artefacts are expected to do what its de- } \\
\text { signers intend them to do }\end{array}$ & $\begin{array}{l}\text { De Paoli et al-2019. The spatial context of organizations: A critique of } \\
\text { creative workspaces'. Journal of Management \& Organization }\end{array}$ \\
\hline Ensemble view & $\begin{array}{l}\text { ICT is analysed in association with organi- } \\
\text { zational context of use }\end{array}$ & $\begin{array}{l}\text { Toivonen, T. and C. Sorensen The Creative Process in Coworking \& } \\
\text { Collaborative Work: Insights for Executives, Managers \& Designers. } \\
\text { 2018. }\end{array}$ \\
\hline Proxy view & $\begin{array}{l}\text { Key aspects of technology may be cap- } \\
\text { tured through surrogate measures }\end{array}$ & $\begin{array}{l}\text { Clifton, N., A. Füzi, and G. Loudon, Coworking in the digital economy: } \\
\text { Context, motivations, and outcomes. Futures, 2019. (in press): p. 1- } \\
16 .\end{array}$ \\
\hline Computational view & $\begin{array}{l}\text { The focus is on technical features (e.g. } \\
\text { modeling capabilities) of artefacts }\end{array}$ & $\begin{array}{l}\text { Kopplin, C.S., Two heads are better than one: matchmaking tools in } \\
\text { coworking spaces. Review of Managerial Science, 2020. in press: p. } \\
1-25\end{array}$ \\
\hline
\end{tabular}




\section{Limitations and next steps}

- The review of co-working scholarship is not meant to be exhaustive or even necessarily representative

$-\rightarrow$ Our review of papers need to be broadened to include up-to-date studies (after the health-emergence)

Further investigation

- the role of ITC artefacts as 'mediators' that organize and are organized (Holt, 2019)

- the impact of ICT on the daily activities of workers and experiences

- the way in which technology is configured raise issues of power and control. 


\title{
EXTREME CO-WORKING SPACE
}

\section{Thank you!}

\author{
marialaura.toraldo@unimi.it
}

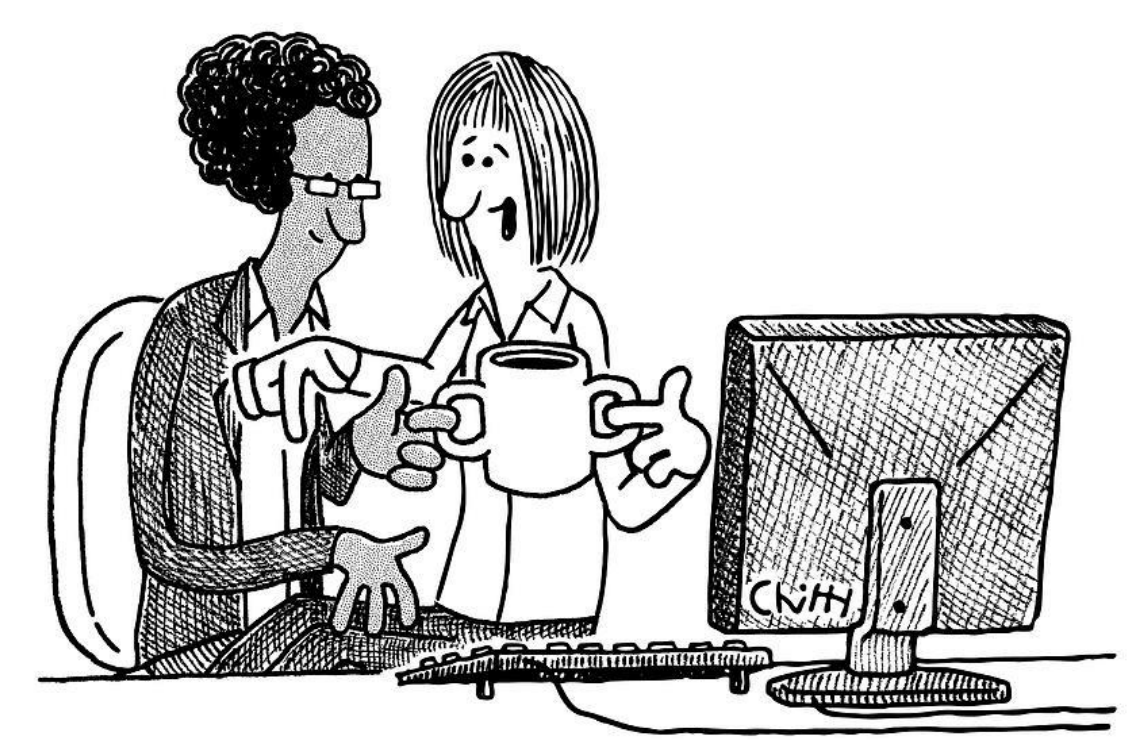

"Give me a shout when you're done with the space bar!" 